\title{
Incorporating circulation statistics in bias correction of GCM ensembles: hydrological application for the Rhine basin
}

\author{
Christiana Photiadou ${ }^{1,2,3} \cdot$ Bart van den Hurk $^{3} \cdot$ Aarnout van Delden $^{1}$ • \\ Albrecht Weerts ${ }^{2}$
}

Received: 8 September 2014 / Accepted: 24 March 2015 / Published online: 7 April 2015

(C) The Author(s) 2015. This article is published with open access at Springerlink.com

\begin{abstract}
An adapted statistical bias correction method is introduced to incorporate circulation-dependence of the model precipitation bias, and its influence on estimated discharges for the Rhine basin is analyzed for a historical period. The bias correction method is tailored to time scales relevant to flooding events in the basin. Large-scale circulation patterns (CPs) are obtained through Maximum Covariance Analysis using reanalysis sea level pressure and high-resolution precipitation observations. A bias correction using these CPs is applied to winter and summer separately, acknowledging the seasonal variability of the circulation regimes in North Europe and their correlation with regional precipitation rates over the Rhine basin. Two different climate model ensemble outputs are explored: ESSENCE and CMIP5. The results of the CP-method are then compared to observations and uncorrected model outputs. Results from a simple bias correction based on a delta factor (NoCP-method) are also used for comparison. For both summer and winter, the CP-method offers a statistically significant improvement of precipitation statistics for subsets of data dominated by particular circulation regimes, demonstrating the circulation-dependence of the precipitation bias. Uncorrected, $\mathrm{CP}$ and NoCP corrected model outputs were used as forcing to a hydrological model to simulate river discharges. The CP-method leads to a larger improvement in simulated discharge in the Alpine area in
\end{abstract}

Christiana Photiadou

christiana.photiadou@knmi.nl

1 Institute for Marine and Atmospheric Research, Utrecht University, P.O Box 80.005, 3508 TA Utrecht, The Netherlands

2 Deltares, P.O Box 177, 2600 MH Delft, The Netherlands

3 KNMI, P.O. Box 201, 3730 AE De Bilt, The Netherlands winter than in summer due to a stronger dependence of Rhine precipitation on atmospheric circulation in winter. However, the NoCP-method, in comparison to the $\mathrm{CP}$ method, improves the discharge estimations over the entire Rhine basin.

Keywords Bias correction - Circulation patterns · Maximum Covariance Analysis · Seasonal discharges

\section{Introduction}

Hydrological projections of climate change for the Rhine basin are a valuable asset in water management, impact modeling, and decision-making and climate adaptation studies. To quantify projected changes in hydrological impact studies, trends and changes in past and future climate are usually assessed using global climate models (GCMs). A bias correction on the GCM outputs is essential to obtain realistic, useful and usable hydrological simulations (Wilby et al. 1998a; Fowler et al. 2007; Maraun et al. 2010). Among others (Buishand and Brandsma 1996; Hagemann et al. 2011; Goodess et al. 2012; van Pelt et al. 2012) applied downscaling methods to correct climate model outputs of meteorological variables using observation data. Although uncertainties in precipitation and temperature outputs for future periods are generally reduced by bias correction methods, a systematic analysis of the origin of the bias for present day conditions is usually not included. One known cause of systematic precipitation or temperature biases in GCMs is an error in the representation of atmospheric circulation statistics, with a potentially large implication for the reliability of the future projections of these modeling systems (Van Haren et al. 2012; Wang et al. 2014). 
Precipitation bias in climate models is primarily related to coarse resolution, lack of ability to simulate explicitly local processes, misrepresentation of physical processes, all of which can in some areas be amplified by feedbacks between climate components (Wang et al. 2014). In Central Europe, model biases in sea surface temperature contribute to the precipitation bias, although precipitation changes in this area are primarily caused by circulation changes (van Ulden and van Oldenborgh 2006; van Haren et al. 2013). Depending on the area of interest and the physical processes dominating the precipitation biases, we set up a framework to perform a correction of the circulation dependent precipitation bias.

The climate in Europe-and subsequently the local climate and the hydrological response of the Rhine basin-is strongly influenced by the variability of the atmospheric circulation and the unstable nature of the North-Atlantic dynamics-especially in wintertime (Stahl and Demuth 1999; Frei et al. 2001; Haylock and Goodess 2004; Pfister et al. 2004; Tu 2006; Bárdossy 2010b; Cattiaux et al. 2012). Circulation variability plays an important role in determining changes in the temporal and spatial distributions of climatological variables such as precipitation and temperature (Wibig 1999; Slonosky et al. 2000).

Previous studies have included atmospheric variability in methods for model bias correction by conditioning existing methodologies such as quantile regression, quantile mapping and weather generators (resampling) on the governing circulation regime (Wilby et al. 1998b; Huth 1999; Clark et al. 2004; Friederichs and Hense 2007; Hundecha and Bárdossy 2008; Jagger and Elsner 2009; Bárdossy and Pegram 2011).

In this study we adapt the well-known delta factor bias correction method to distinguish between different atmospheric circulation patterns (CPs) for winter and summer precipitation variability. The proposed correction is labeled as the CP-method due to the incorporation of circulation pattern dependent bias correction coefficients. The prevailing circulation regimes in the North European region, responsible for the majority of precipitation variability in the Rhine basin, are derived using an observational record encompassing the period 1961-2005. Using the CPs, we introduce a correction to model precipitation output: the background of the bias may depend on the particular CP, and thus require a different correction. For example, highpressure precipitation bias can be associated to model bias in wet-day frequency (Suklitsch et al. 2011), while persistent low pressure conditions may generate errors related to advection or precipitation formation (Christensen et al. 1997). The frequency of the circulation patterns from the climate models is compared to the ERA-I frequency distribution. However, no attempt was made to apply a correction to a bias in the $\mathrm{CP}$ frequency distribution, as we focus on the correction of the precipitation output for a specific circulation regime.

A method which does not consider circulation regimes but only corrects model precipitation outputs using the standard delta method is labeled here as NoCP-method. The CP-method introduces extra parameters in the correction because of the use of circulation statistics for each precipitation bias-depended subset. The dependence of bias correction coefficients on circulation patterns reduces the overall statistical performance of the CP-method due to the reduction of the sample size used to calibrate every bias correction coefficient. This trade-off between case-specific bias correction coefficients and reduced sample size will be discussed further below.

The circulation patterns are derived through the Maximum Covariance Analysis (MCA, Von Storch and Zwiers 1999; Polade et al. 2013), which objectively finds patterns that optimally explain the winter/summer precipitation variability of the entire Rhine basin. The frequency of occurrence of these CPs is evaluated in two ensembles of GCM simulations: the ESSENCE climate model ensemble (Sterl et al. 2008) and the CMIP5 ensemble (Taylor et al. 2012). For each model non-linear precipitation correction factors are derived. The robustness of the CP-method is tested regarding improvements in precipitation and estimated extreme discharges for the Rhine basin. First, to assess the effect of the CP-method, we compare the spread of the GCM ensembles to the uncorrected model data and the results from the NoCP method. Second, we investigate the impact of the bias correction from the CP-method on estimated discharges by comparison with discharge calculations based on uncorrected and corrected GCM precipitation data. The correction is applied on 5 day precipitation sums. The selection of 5 day sums is in alignment with the targeted hydrological application in the Rhine basin. The CP-method accounts for changes in the mean and extreme precipitation averaged over a given time interval. Kew et al. (2011) found that the bias present in ESSENCE precipitation in the Rhine basin varies with the averaging length. In particular, biases in the wet day frequency are present in 1 day precipitation sums, while in 10- and 20-days sums these biases are insignificant. Biases for the 50 and $99 \%$ quantiles are distinct for 10- and 20-day sums. In hydrological applications, extreme discharges in the Alpine region generally result from extreme multi-day precipitation amounts in the river basin (Ulbrich and Fink 1995; Disse and Engel 2001). This has motivated our selection of 5-day intervals.

A detailed description of the MCA, the data sets used, and the bias correction method follows in Sect. 2. Section 3 presents the derived circulation patterns from the MCA analysis for winter and summer for the period 1961-2005. Also shown are the results from the bias correction and the 
contribution of the proposed CP correction. Section 4 discusses the results and summarizes the conclusions.

\section{Materials and methods}

\subsection{Area and data details}

\subsubsection{Precipitation observations}

The precipitation data set used in this study is a new highresolution set covering 134 sub-catchments of the Rhine basin for the period of 1961-2008. The CHR precipitation set (covering 1961-1995; Sprokkereef 2001) was extended with more recent data sets from Germany, Switzerland and France and is referred to as CHR08 (Photiadou et al. 2011). Photiadou et al. (2011) showed that with the HBV-96 hydrological model, the CHR08 data set generates significantly improved extreme discharge statistics compared to alternative precipitation data sets (E-OBS and ERA-Interim precipitation data sets).

\subsubsection{Sea level surface pressure data}

An extended daily sea level pressure (SLP) record for 1961-2005 is constructed by combining ECMWF ERA40 (1961-1978; Uppala et al. 2005) and ERA-Interim (19792005; Dee et al. 2011) SLP reanalysis data. Prior to this, ERA40 SLP data were interpolated to the ERA-I grid and their SLP characteristics were compared for the overlapping years. A comparison of the pressure anomalies and their frequencies between ERA40 and ERA-I show that they are very similar, allowing the combination of the two datasets (not shown here). The extended SLP record is referred to as ERA-SLP and contains daily averaged SLP data on a common $1.5 \times 1.5$ latitude/longitude grid. The SLP fields cover the area $-4.5^{\circ} \mathrm{W}$ to $25^{\circ} \mathrm{E}$ longitude and $32^{\circ} \mathrm{N}-63^{\circ} \mathrm{N}$ latitude (Fig. 1). The time period of 1961-2005 was selected to match the observed precipitation record (see below) and the historical record of CMIP5 outputs.

\subsubsection{ESSENCE}

ESSENCE (Ensemble SimulationS of Extreme weather events under Nonlinear Climate changE, Sterl et al. 2008) is a 17-member ensemble global climate simulation covering 1950-2100, generated using the ECHAM5/MPI-OM coupled climate model. Simulations are carried out at a horizontal resolution of T63 (roughly $2.5^{\circ}$ ) and 31 vertical atmospheric levels, and are forced by the SRES A1b scenario (Nakicenovic and Swart 2000). Perturbing the initial state of the atmosphere, different ensemble members are formed. Using a large ensemble of climate simulations

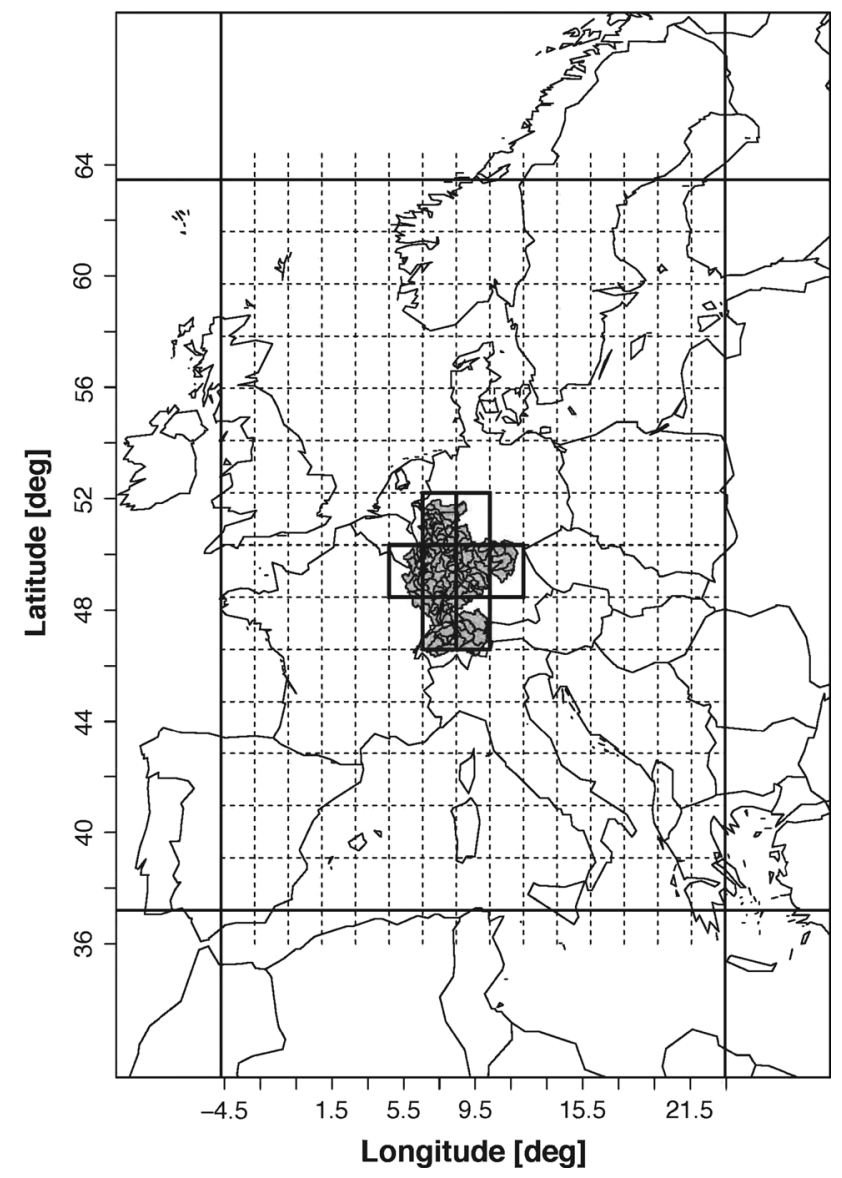

Fig. 1 Sea level pressure interest domain (large rectangle enclosing gridded area), with the 134 sub-catchments of the Rhine river (grey shading, black outline) used for the Maximum Covariance Analysis. Grey dashed lines indicate the grid boxes onto which all GCMs were interpolated and the bias correction was applied. Thick solid black lines indicate the 8 grid cells covering the Rhine basin where the bias correction method is applied

helps to distinguish internal variability from systematic trends induced by changed external forcing. The large sample also allows a better quantification of changes in extreme values of climate variables (large return periods; Sterl et al. 2008). Precipitation and sea level pressure data outputs were retrieved from the climate model.

\subsubsection{CMIP5 climate models}

Precipitation and sea level pressure data outputs were also retrieved from the multi-model World Climate Research Programme (WCRP) Coupled Model Intercomparison Project phase 5 (CMIP5; Taylor et al. 2012), prepared for the IPCC assessment report AR5. Here, 19 models from the CMIP5 dataset were used, having no missing values in either SLP or precipitation for the historical period (as for ESSENCE also), chosen to overlap the observational record 1961-2005 (similar climate forcings). 


\subsection{Methods}

The proposed methodology is split into three steps (Fig. 2). The first step concerns the MCA, also known as singular value decomposition (SVD), the retrieval of the circulation patterns and their frequency, while the second step incorporates the circulation statistics derived from the MCA into the bias correction method. The third step is the hydrological application. Here, the uncorrected and the bias corrected ( $\mathrm{CP}$ and NoCP) precipitation model outputs are used as forcing to the HBV-96 hydrological model to estimate extreme discharge for the Rhine basin.

\subsubsection{Maximum Covariance Analysis and principal components}

The circulation patterns that are related to the hydroclimatological variables of the Rhine basin are obtained using MCA. MCA identifies pairs of SLP and precipitation fields, characterized by high covariance, and the time evolution of their expression in the source data [principal components (PCs)]. Several studies applied MCA to a combination of meteorological and hydrological fields to link large-scale circulation patterns to local rainfall/temperature variability (Bertacchi Uvo et al. 2001; Castaings et al. 2009; Martín et al. 2011). Extended descriptions on MCA analysis can be found in Bretherton et al. (1992), Von Storch and Navara (1995), and Von Storch and Zwiers (1999).

In our study, MCA is applied to the cross-covariance matrix of two spatial-temporal fields of daily mean ERA SLP and CHR08 precipitation in the time period 19612005. These fields encompass different spatial areas and resolutions (Fig. 1). The SLP domain selection encompasses atmospheric circulation systems that are potential

\section{(a)}

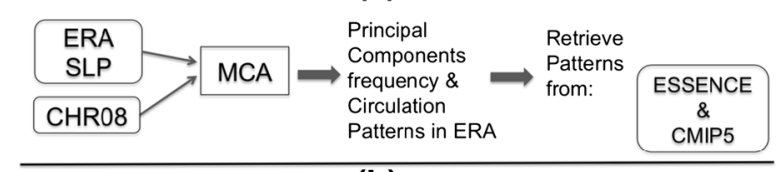

(b)

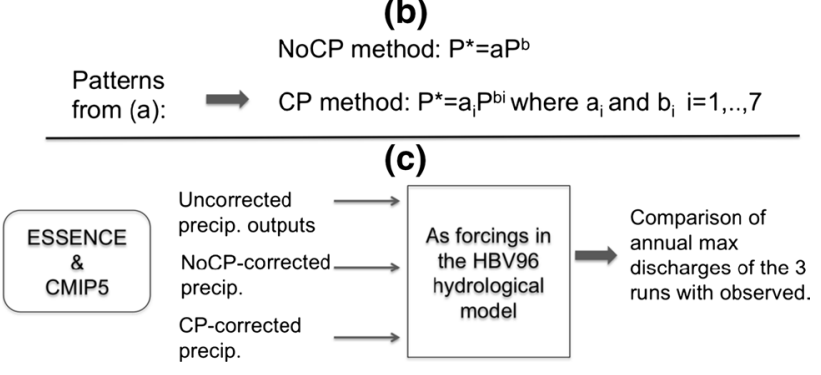

Fig. 2 Diagram of the bias correction and its subsequent analysis steps. Symbols and equations are explained in the methodology section. a Maximum Covariance Analysis and pattern frequency, b CP delta factors correction, $\mathbf{c}$ hydrological application drivers of precipitation events over Central Europe and potential flooding events in the Rhine basin (Jones and Lister 2009). To test the robustness of the MCA, the calculation of PCs using the geopotential height at $500 \mathrm{hPa}$ instead of SLP led to similar PCs. The CHR08 data were weighted with the area size of each sub-catchment. Five day mean and standard deviation was selected to standardize the SLP and precipitation data.

Two seasonal periods are distinguished: winter (October, November, December, January, February, March) and summer (April, May, June, July, August, September). The MCA was implemented for both seasons separately. The relation between the two variables is explained through the constructed covariance matrix, explained below.

The notation used here is as follows: a time series is denoted by $(t)$, a vector by a boldface letter and a matrix by a capital boldface letter. $\mathbf{X}_{m l}$ denotes the ERA SLP data grid points $m=1, \ldots, 400, \mathbf{Y}_{n l}$ refers to the CHR08 precipitation data with sub-catchments $n=1, \ldots, 134$ and $l$ is the number of time steps. The cross-covariance matrix $\mathbf{C}_{m n}$ of $\mathbf{X}_{m l}$ and the transposed (T) $\mathbf{Y}_{n l}$ is constructed through:

$\mathbf{C}_{m n}=\mathbf{X}_{m l} \cdot T\left(\mathbf{Y}_{n l}\right)$.

The MCA of $\mathbf{C}_{m n}$ solves the following equation:

$\mathbf{C}_{m n}=\mathbf{U}_{m m} \mathbf{D}_{\text {diag_nn }} \mathbf{V}_{n n}^{T}$,

where $\mathbf{U}_{m m}$ and $\mathbf{V}_{n n}$ represent the spatial anomalies of SLP and precipitation respectively, and $\mathbf{D}_{\text {diag_nn }}$ the array of singular values at the diagonal of the matrix, describing the fraction of the explained covariance (EV) between the two variables. The column vectors of $\mathbf{U}$ and $\mathbf{V}$ are the singular vectors and satisfy the orthogonal relation $\mathbf{u}_{i} \mathbf{u}_{j}^{T}=\mathbf{u}_{j}^{T} \mathbf{u}_{i}=\mathbf{I}$ and $\mathbf{v}_{i} \mathbf{v}_{j}^{T}=\mathbf{v}_{j}^{T} \mathbf{v}_{i}=\mathbf{I}$, with $\mathbf{I}$ the identity matrix. The circulation patterns (CPs) that are well correlated to fields of precipitation variability in the CHR08 database are thus contained in $\mathbf{U}$.

To construct the principal components of each mode the following equation is applied:

$P C_{E R A}=\sum \mathbf{X}_{m l} \cdot \mathbf{U}_{m m}$

where the $P C_{E R A}$ is the principal component of the SLP modes.

\subsubsection{Projections of ESSENCE and CMIP5 SLP on MCA-derived spatial patterns}

Here, we used 5 day precipitation sums and SLP fields, of ESSENCE and CMIP5 ensemble, all interpolated to the same grid (Fig. 1). The circulation dependent bias correction of the climate model ensembles ESSENCE and CMIP5 is driven by the CPs, which were derived using MCA. The PCs of the spatial SLP anomalies in the climate 
model ensembles are constructed by projecting $\mathbf{U}$ on the gridded SLP data of ESSENCE and CMIP5 models, $\mathbf{E}_{m l}$, similar to Eq. (3):

$P C_{M o d}=\sum \mathbf{E}_{m l} \cdot \mathbf{U}_{m m}$

For each day in the climate model records a dominant $\mathrm{CP}$ is identified by selecting the pattern with the largest value of its principal component $\left(\mathrm{PC}_{\mathrm{Mod}}\right)$. Each day is categorized according to its dominant PC (selected from the first three PCs) and its amplitude sign. This leads to 6 circulation pattern classes, CP1-CP6. Days for which another PC than one of the first three appears to be the dominant pattern are classified in a "residual" class, CP7. The most frequently occurring $\mathrm{CP}$ in a 5 day interval defines all the 5 days within the interval.

This leads to a frequency distribution of dominant CPs that can be compared to a respective distribution in the ERA-SLP database, allowing an evaluation of the models ability to reproduce the circulation statistics associated with the local precipitation of the Rhine basin. We derive 7 $\mathrm{CP}$ categories for both the observations, ERA-SLP and the model ensembles, ESSENCE and CMIP5; PC 1-3 (positive amplitudes) are CP 1-3 and CP 4-6 are the negative amplitudes of the PCs $1-3$. The rest of the PCs are classified into one category as $\mathrm{CP} 7$ (residuals).

\subsubsection{The bias correction method: CP-method}

A non-linear bias correction is used in which the modeled daily precipitation $P$ is transformed by:

$P^{*}=a P^{b}$,

where $a$ and $b$ are the transformation coefficients $(a, b>0)$. Leander and Buishand (2007) used this type of transformation to correct for bias in regional climate model simulations for the Meuse basin. Van Pelt et al. (2012) applied this equation in observed precipitation to account for future changes in precipitation for the Rhine basin, where an excess correction accounted for days with precipitation above a given (high) quantile to correct extreme events. Here we apply this excess correction for model precipitation $P>q_{\text {mod }}^{95}$ and $b>1$, where $q_{\text {mod }}^{95}$ is the 95 th quantile of the model precipitation.

In this study, we adopt the procedure described in Leander and Buishand (2007) to retrieve $a$ and $b$ coefficients specified for each collection of days where one of the seven CPs categories is found to be dominant. Doing so we obtain 7 pairs of transformation coefficients $a$ and $b$, one pair for each CP. The coefficients $a$ and $b$ are derived using the equations:

$$
\begin{aligned}
& b_{C P}=\log \left(q_{\text {obs_CP }}^{95} / q_{\text {obs_CP }}^{60}\right) / \log \left(q_{\text {mod_C } C P_{i}}^{95} / q_{\text {mod_CP }}^{60}\right) \text { and } \\
& a_{C P}=q_{\text {obs_C } C P_{i}}^{60} /\left(q_{\text {mod_C } C P_{i}}^{60}\right)^{b},
\end{aligned}
$$

where $q_{o b s}^{60}, q_{o b s}^{95}$ are the 60th and 95th quantiles of the observations (CHR08), $q_{\text {mod }}^{60}, q_{\text {mod }}^{95}$ are the corresponding quantiles of the model precipitation and each category is represented by the index $C P_{i}=1, \ldots, 7$. For extreme events $\left(P>q_{\text {mod }}^{95}\right)$ Eq. (5) is transformed into:

$$
\begin{aligned}
& P_{C P}^{*}=\bar{E}_{\text {mod_CP }} / \bar{E}_{\text {obs_CP }}\left(P_{C P}-q_{\text {mod_CP }}^{95}\right) \\
& +a_{C P i}\left(q_{\text {mod_C } C P_{i}}^{95}\right)^{b_{C P i}},
\end{aligned}
$$

with $\bar{E}_{\text {mod }}, \bar{E}_{\text {obs }}$ the mean model and observed precipitation excess respectively. The bias correction descripted here is further refer to as the CP-method. The classic delta factors correction is labeled here as the NoCP-method and used in the results section for comparison purposes.

\subsection{Hydrological application}

The uncorrected, NoCP and CP corrected precipitation outputs are used as forcings in the HBV-96 hydrological model (Bergström and Forsman 1973; Bergström 1976; Lindström et al. 1997) to estimate the annual maximum discharges for the Rhine River. The HBV-96 hydrological model is a semi-distributed conceptual hydrological model originally developed at the Swedish Meteorological and Hydrological Institute (SHMI) in the 1970s. The HBV-96 precipitationrunoff model of the Rhine river basin has been successfully used, for instance, to estimate extreme runoff from catchments or to quantify the impacts of predicted climate changes (Berglöv et al. 2009). HBV-96 describes the most important runoff generating processes. The model consists of subroutines for snow accumulation and melt, a soil moisture accounting procedure, routines for runoff generation and a simple routing procedure. A complete description of the HBV-96 calculation scheme and model structure for the Rhine basin can be found in Eberle et al. (2005) and Sprokkereef (2001). Photiadou et al. (2011) showed that in the Rhine basin, the temperature effect did not have a significant influence on the estimation of extreme discharges. Following this study, temperature forcings in all simulations were derived from E-OBS Version 7 gridded data (Haylock et al. 2008). The E-OBS gridded temperature data set was made available from the ENSEMBLES project (Haylock et al. 2008), where it was constructed for validation of RCMs and for climate change studies. The spatial resolution of this data set is $0.25^{\circ}$ by $0.25^{\circ}$ on a regular latitude-longitude grid. 
Table 1 Explained variance (EV \%) as derived from the MCA for the 9 first pairs of the principal components of SLP and precipitation for winter and summer season

\begin{tabular}{lllllllllll}
\hline EV $(\%) /$ PC & PC1 & PC2 & PC3 & PC4 & PC5 & PC6 & PC7 & PC8 & PC9 & S1-9 \\
\hline Winter & 54.4 & 15.8 & 5.6 & 5.2 & 3.5 & 2.4 & 1.7 & 1.5 & 1.3 & 91.4 \\
Summer & 46.8 & 12.8 & 7.8 & 6.8 & 4.7 & 3.1 & 2.2 & 1.6 & 1.3 & 87.1 \\
\hline
\end{tabular}

S1-9 is the sum of the EV for the 9 first PCs

\section{Results}

\subsection{SLP Patterns and their frequency distribution}

\subsubsection{Principal components of co-varying SLP and precipitation patterns}

The co-varying SLP and precipitation patterns found by the MCA are ranked with respect of their contribution to the total explained (co)variance (EV). Table 1 presents the explained variance (EV) of the first nine pairs of SLP and precipitation principal components for winter and summer seasons. Summed together, the first three pairs of the principal components already cover a significant fraction of EV. The remaining patterns show little coherence and can therefore be considered to reflect noise. Three principal components are therefore retained for winter and summer season, respectively, explaining approximately $70 \%$ of the total co-variance in each season. Furthermore, the physical representation of the $\mathrm{PC}$ showed insignificant patterns.

\subsubsection{Frequency distribution of Principal Components}

In Fig. 3, the frequency distribution of the principal components for winter and summer season for ERA-SLP is shown together with the respective frequency in the CMIP5 and ESSENCE climate model ensembles diagnosed by their dominant correspondence to the SLP patterns. Also shown is the $95 \%$ range of the probability density obtained from the individual ESSENCE members, and the individual values of the CMIP5 models. In winter (Fig. 3a), ESSENCE displays a lower fraction of days attributed to PC1 than ERA, while CMIP5 models show a good frequency for most models, a number of them showing lower frequencies. For PC2, ESSENCE has the right ensemble mean fraction of days, while the ensemble spread is smaller than the CMIP5 ensemble, where a large number of models have higher fractions of days assigned to PC2 than ERA. For PC3, the CMIP5 ensemble has a very good agreement with the reference data set, while the ESSENCE mean is biased. For the summer season (Fig. 3b) CMIP5 models tend to overestimate the presence of PC1 and PC3. ESSENCE also overestimates $\mathrm{PC} 1$ but has a very good agreement with ERA concerning PC3. Both ESSENCE and CMIP5 underestimate the mean fraction of days where PC2 is dominant, with a similar ensemble spread. In summary, the ESSENCE ensemble shows a smaller bias in the frequency distribution of PC's than CMIP5 in both seasons.

\subsubsection{Circulation patterns derived from the MCA for winter and summer}

The leading CPs and their corresponding precipitation fields for the winter half year are shown in Fig. 4. The first field (Fig. 4a) illustrates a low-pressure anomaly (LA) in Central Europe and a high-pressure anomaly in Southwestern Europe. This implies a suppressed zonal Westward flow over the Rhine basin, producing relatively wet winter weather. The associated precipitation pattern (Fig. 4b) has overall positive anomalies across the basin with an exception of the southeastern catchment in the Swiss basin which is influenced by local topography. This resulting pattern is linked to past flood events in the Rhine basin (Bárdossy and Pegram 2011). The pair of fields with opposite sign is a high-pressure anomaly covering Central Europe, is associated with negative precipitation anomaly. This first pair of the MCA explains around $55 \%$ of the total EV (Table 1).

In the second winter pattern (explaining almost $16 \%$ of the EV, Fig. $4 \mathrm{c}, \mathrm{d}$ ), a strong zonal flow similar to the positive phase of the North Atlantic Oscillation (NAO+) (Hurrell 1995; Zveryaev 2009) is associated with precipitation variations in the Rhine basin dominated by enhanced atmospheric moisture advection with excessive precipitation over northern Europe and deficient precipitation over southern Europe. Many studies identified the NAO as a driver of winter precipitation in Northern Europe (Haylock and Goodess 2004). High streamflow anomalies during autumn season were associated with the positive phase of the NAO (Ionita et al. 2011).

The last winter pattern (Fig. 4e, f) we consider here represents a meridional flow with south to north air transport (MerSN). It is characterized by positive precipitation variations in the Moselle basin and negative anomalies in eastern Swiss and German basins (Main).

For summer, the first SLP variation (Fig. 5a) explains around $47 \%$ of the total co-variance and depicts a strong high-pressure anomaly (HA) with westward flow dominating the European continent, and positive precipitation anomalies (Fig. 5b). The second SLP pattern (Fig. 5c) represents the 


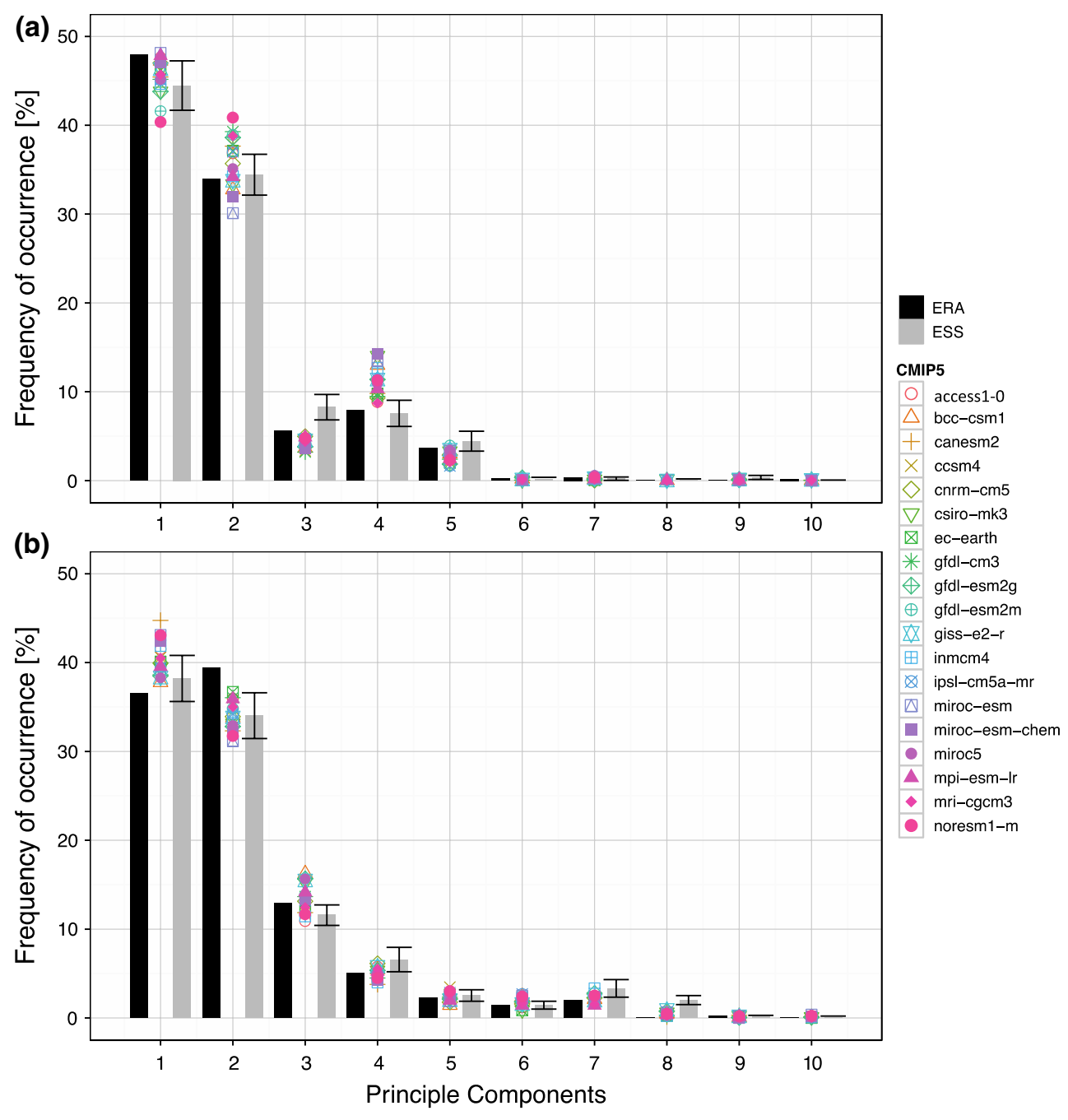

Fig. 3 Frequency of the dominant principal components of 5 days of SLP for ERA (black bars), ESSENCE ensemble (grey bars) and CMIP5 models (different colors and shapes) for $\mathbf{a}$ winter and $\mathbf{b}$ sum-

analogy of a positive phase of NAO (NAO+). The Southern European high-pressure anomaly dominates the regional precipitation variations of the Rhine; negative precipitation anomalies for the majority of the (mainly southern) subcatchments and positive anomalies for the Lower Rhine (Fig. 5d). The meridional flow (Fig. 5e) with south to north air transport (MerSN) produces negative precipitation anomalies for eastern Swiss sub-catchments and positive precipitation anomalies mainly for the Moselle basin (Fig. 5f).

\subsection{Bias correction of precipitation}

\subsubsection{Coefficients used in the correction algorithm}

Five-day precipitation sums of ESSENCE and CMIP5 are corrected using the CP-method. The method is applied mer season. Error bars indicate the $95 \%$ range of probability from the individual ensemble members

both to gridded ( 8 grid points, Fig. 1) and domain averaged precipitation outputs. The summary results of the domain average correction are shown below (Table 2; Figs. 7, 8, 9). The correction at grid level is performed to allow the use of the hydrological model, which demands gridded input data. Corresponding results of the NoCP-method are derived similarly using the same $\mathrm{CP}$ classifications as in the CP-method.

Table 2 shows the statistical summary of the transformation coefficients for area averaged winter and summer precipitation for each of the ESSENCE members, including their mutual standard deviation. The frequency of each $\mathrm{CP}$ in ERA is presented for both winter and summer. The spread between the coefficients derived for the different CPs (CP-method) is considerable: it well exceeds the internal variability of the coefficients in the NoCP method. 
Fig. 4 SLP anomalies (left column) with associated sub-catchment precipitation anomalies (right column), both derived from MCA. Blue lines indicate negative SLP anomalies while red lines show the opposite. Both fields are normalized by subtracting the mean and dividing by the standard deviation of the 5 day running mean and standard deviation. Results shown are for winter half year season (1961-2005). a Low pressure anomaly (LA), b precipitation anomaly, c $\mathrm{NAO}+$ pressure anomaly, $\mathbf{d}$ precipitation anomaly, e MerSN pressure anomaly, $\mathbf{f}$ precipitation anomaly (a)

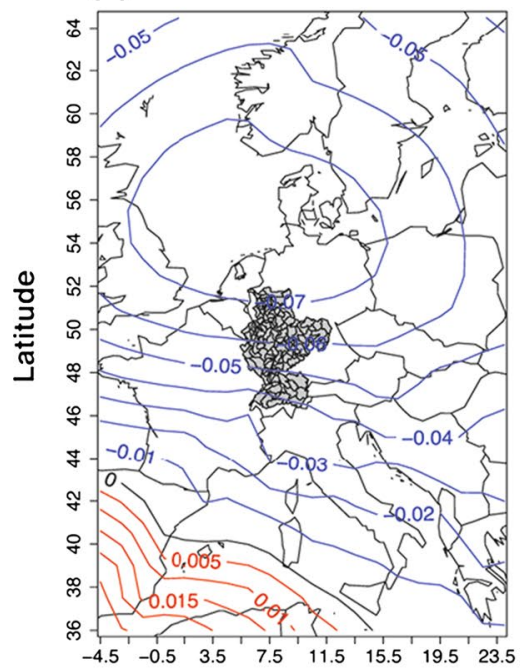

(c)

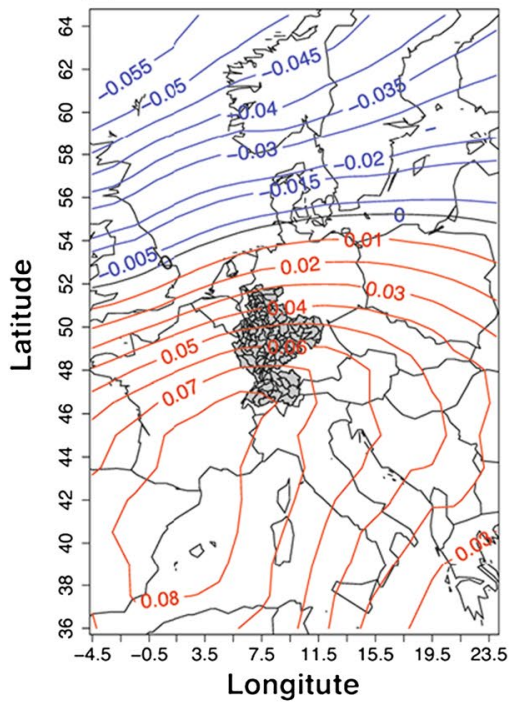

(e)

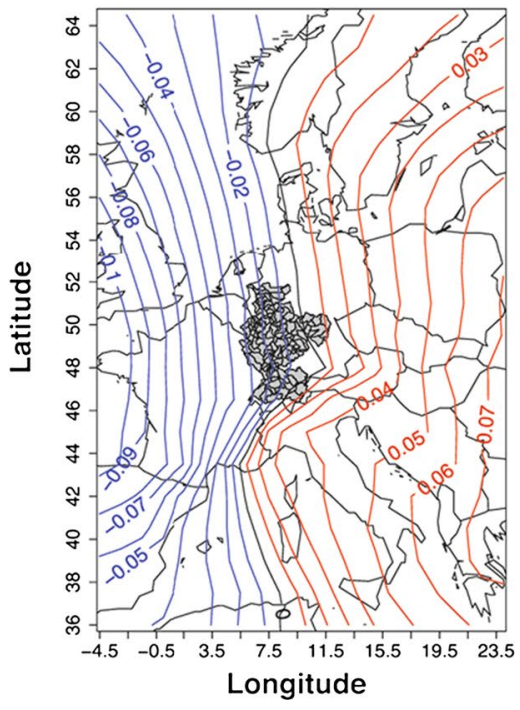

(b)

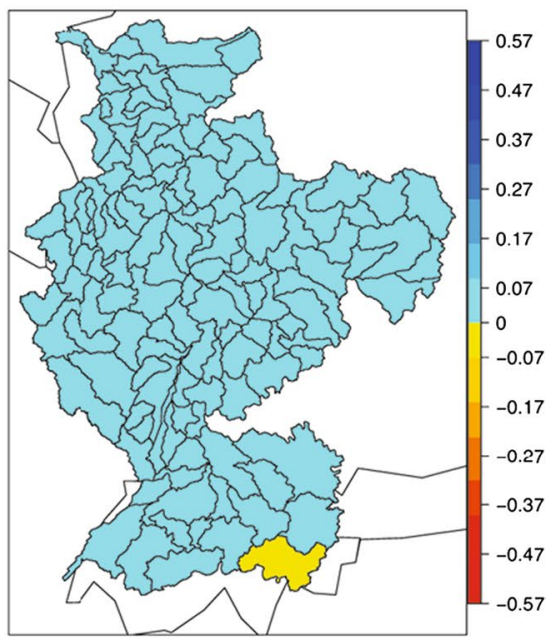

(d)

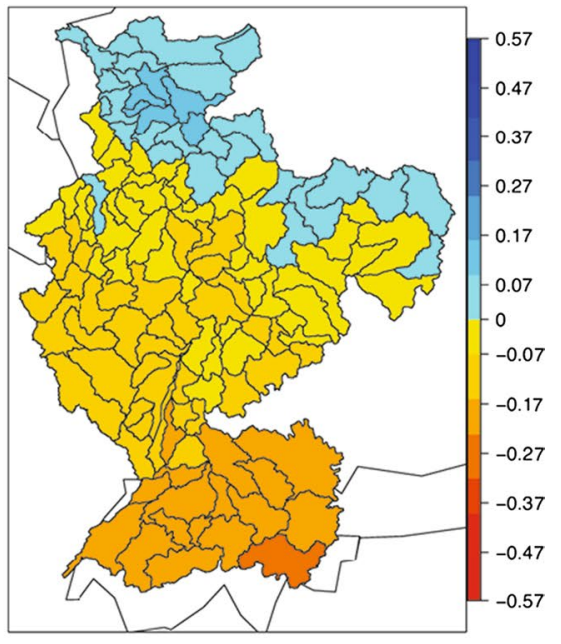

(f)

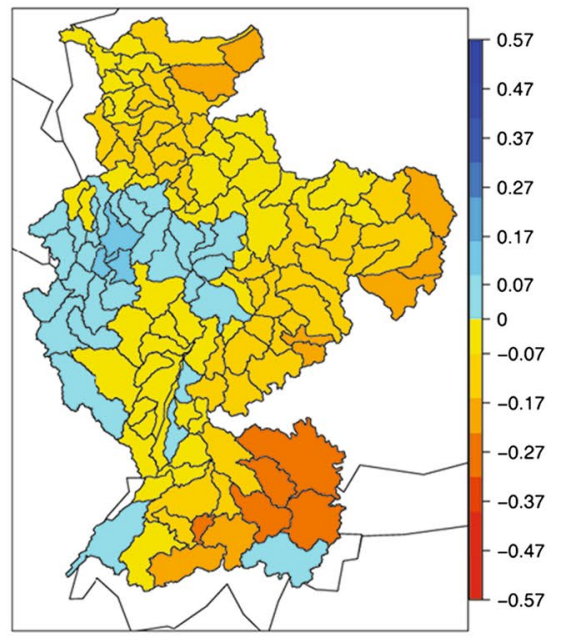


Fig. 5 SLP anomalies (left column) with associated sub-catchment precipitation anomalies (right column), both derived from MCA. Blue lines indicate negative SLP anomalies while red lines show the opposite. Both fields are normalized by subtracting the mean and dividing by the standard deviation of the 5 day running mean and standard deviation. Results shown are for summer half year season (1961-2005). a High pressure anomaly (LA), b precipitation anomaly, c $\mathrm{NAO}+$ pressure anomaly, $\mathbf{d}$ precipitation anomaly, e MerSN pressure anomaly, $\mathbf{f}$ precipitation anomaly (a)

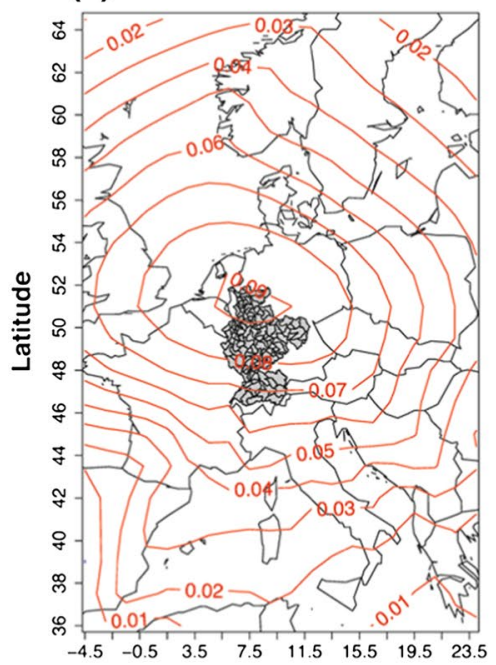

(b)

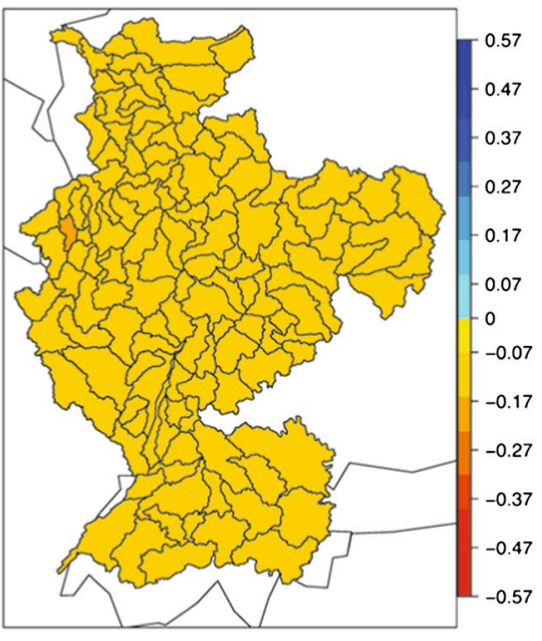

(c)

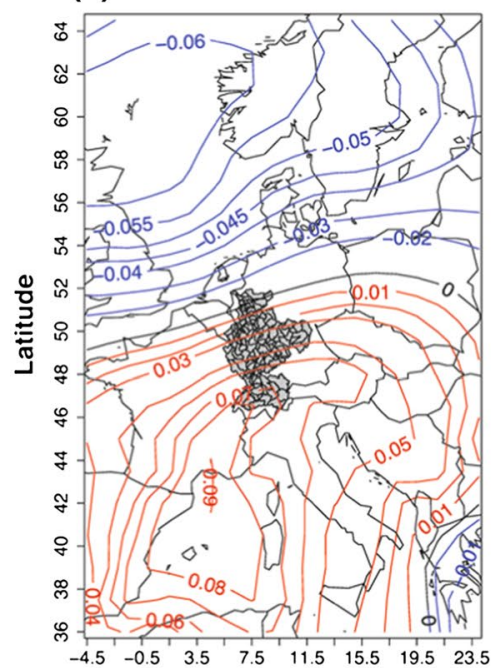

(d)
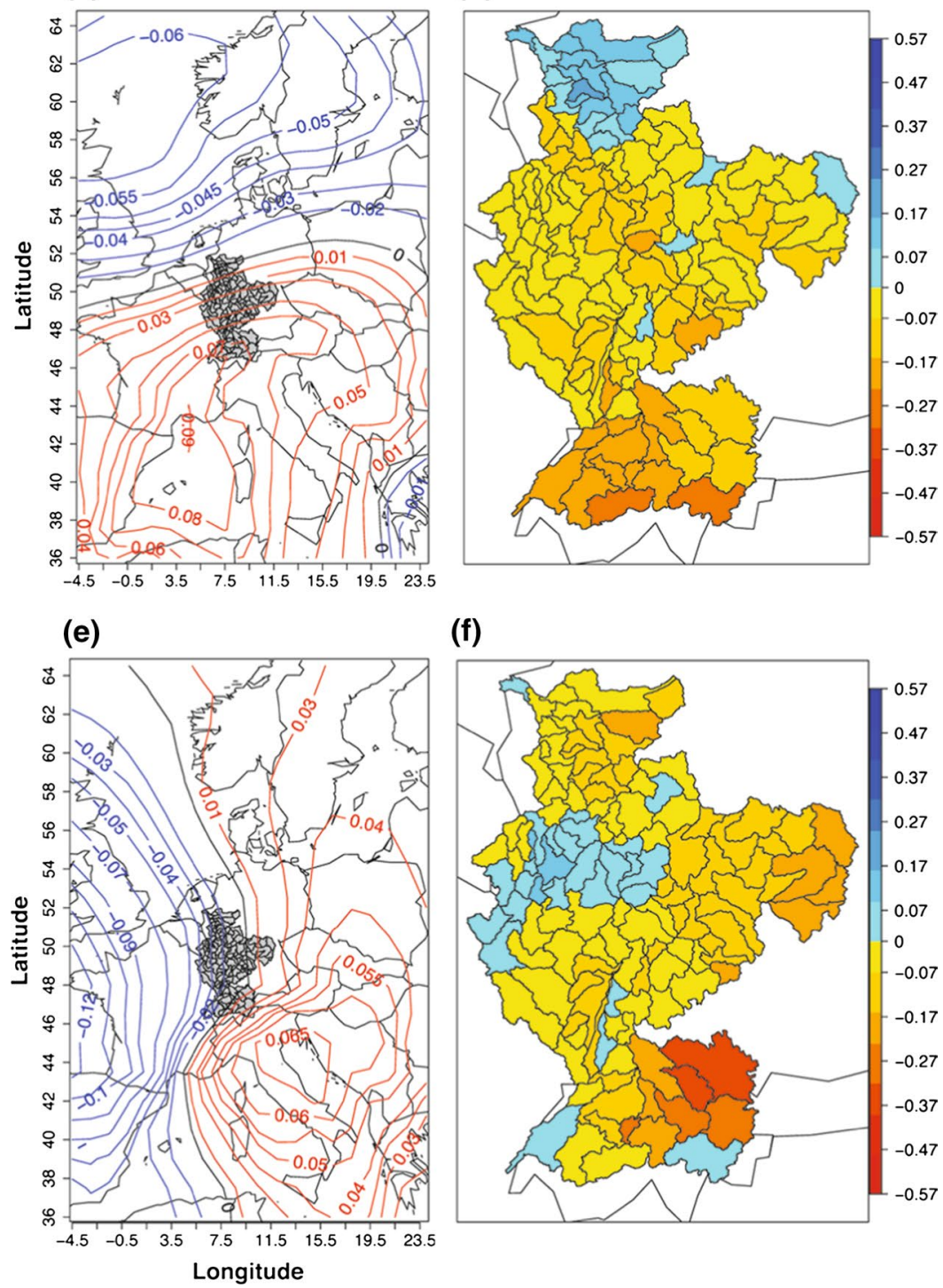

(f)

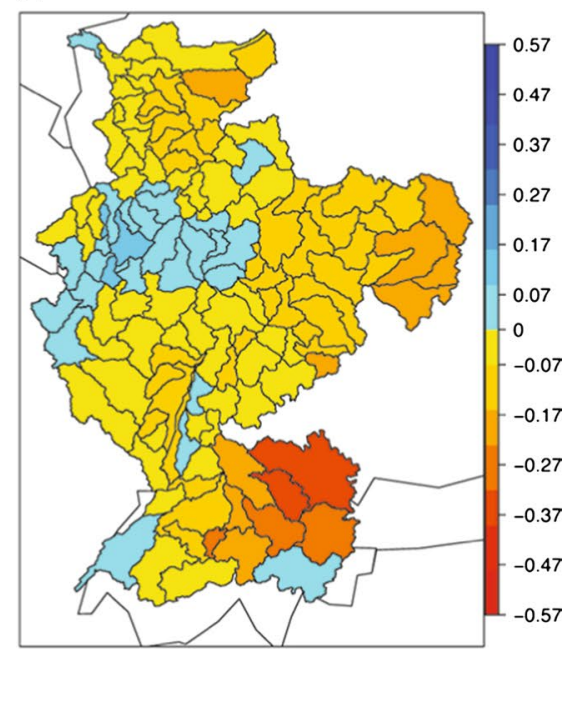


Table 2 Mean and standard deviation of $a$ and $b$ coefficients for ESSENCE (where the spread is over the individual ensemble members), for winter and summer season

\begin{tabular}{|c|c|c|c|c|c|}
\hline Winter & $A$ & $B$ & Summer & $A$ & $B$ \\
\hline NoCP-method & $0.28 \pm 0.04$ & $1.31 \pm 0.04$ & NoCP-method & $1.41 \pm 0.14$ & $0.91 \pm 0.03$ \\
\hline CP1: $24.83 \%$ & $1.10 \pm 0.25$ & $1.00 \pm 0.07$ & CP1: $17.85 \%$ & $1.00 \pm 0.22$ & $0.97 \pm 0.08$ \\
\hline CP2: $18.29 \%$ & $0.04 \pm 0.02$ & $1.80 \pm 0.16$ & CP2: $18.92 \%$ & $3.90 \pm 0.57$ & $0.69 \pm 0.06$ \\
\hline CP3: $2.39 \%$ & $0.05 \pm 0.04$ & $1.80 \pm 0.38$ & CP3: $7.23 \%$ & $1.00 \pm 0.56$ & $0.99 \pm 0.22$ \\
\hline CP4: $25.08 \%$ & $0.10 \pm 0.04$ & $1.60 \pm 0.12$ & CP4: $20.49 \%$ & $1.90 \pm 0.51$ & $0.86 \pm 0.10$ \\
\hline CP5: $16.47 \%$ & $1.90 \pm 0.45$ & $0.90 \pm 0.07$ & CP5: $21.68 \%$ & $0.31 \pm 0.11$ & $1.30 \pm 0.10$ \\
\hline CP6: $2.32 \%$ & $0.13 \pm 0.14$ & $1.90 \pm 0.34$ & CP6: $5.15 \%$ & $4.70 \pm 1.20$ & $0.67 \pm 0.12$ \\
\hline CP7: $10.62 \%$ & $0.15 \pm 0.12$ & $1.60 \pm 0.26$ & CP7: $8.23 \%$ & $1.70 \pm 0.28$ & $0.86 \pm 0.06$ \\
\hline
\end{tabular}

The frequency percentage of each CP in ERA-SLP is also presented for winter and summer

(a)

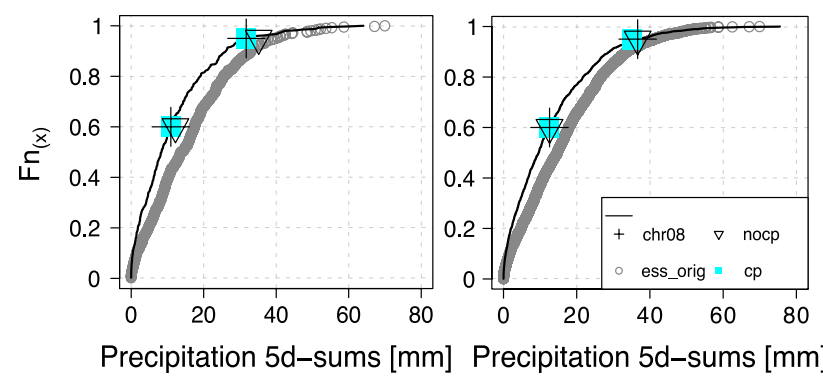

Fig. 6 Illustration of the CP-method for winter precipitation in a single uncorrected ensemble member (raw data shown with grey circles). Black lines denote the observations and black crosses are 60th and 95th percentiles of the observations. In (a) the cumulative distribution of one CP precipitation category is shown, with the corresponding quantiles of each method (blue square for the CP-method; flipped triangle for the NoCP-method). The cumulative distribution of a random entire ensemble member is shown in (b) with the respective 60th and 95th percentiles for both NoCP and CP methods

This variability of regime specific correction coefficients will introduce an extra source of variability in the corrected time series. In particular, CPs with a high frequency of occurrence (e.g. CP1 and CP4 from PC1 in winter and summer) and large deviations of the coefficients from the overall mean will have a relatively large contribution to the overall bias correction.

An illustration of how the CP-method works is given in Fig. 6, where biases in the 60th and 95th percentile of the raw model data are corrected while considering all data in one sample (NoCP) versus applying the correction to a $\mathrm{CP}$ subsample (CP). Figure 6a shows the correction of all 5 day precipitation intervals, which are categorized as a CP1 (low pressure anomaly in winter; Fig. 4a), together with the transformation of the 60th and 95th percentile for both methods. The $\mathrm{CP}$ method improves the distribution of each $\mathrm{CP}$ (Fig. 6a) by matching the two quantiles to the observations better than the NoCP method. For the whole ensemble (Fig. 6b) both CP and NoCP methods make a significant correction for the quantiles, but these corrections are more similar than for the CP1 subsample.

The example in Fig. 6 is further elaborated in Fig. 7, where the two-sided Kolmogorov-Smirnov (K-S) test is applied to the entire data set and the CP subsamples. The $\mathrm{K}-\mathrm{S}$ test is used to test the null hypothesis that the tested distributions have the same characteristics as the distribution of the observations. High $p$ values (in Fig. 7, y-axis) show the significance of the $\mathrm{K}-\mathrm{S}$ test, where $p$ values below 0.05 are insignificant. The CP-method results in both summer and winter are lower than the NoCP results, with the winter results being extremely low. Results are shown for uncorrected model data and corrections according to NoCP and $\mathrm{CP}$ for winter (Fig. 7a) and summer (Fig. 7b). For both seasons, the CP-method shows higher $p$ values than the NoCP method for nearly all CP categories, which demonstrates a good reproduction of the observed cumulative distribution in each CP category. However, for the entire record the NoCP shows a better performance (particularly in winter), due to the stability in calculating the $\mathrm{q}^{95}$ while the CP-method underperforms.

\subsubsection{Application of the method to the CMIP5 model ensemble}

The bias correction was applied to two ensembles, the ESSENCE, as it was mentioned before, and to CMIP5. High return periods ( 50 years) of 5 day precipitation sums of the observations (CHR08), the ESSENCE ensemble and CMIP5 models for both winter and summer are shown in Figs. 8 and 9. The uncorrected ESSENCE precipitation data (Fig. 8a) show a distinct overestimation at low return periods ( $<2$ years) with a small underestimation of precipitation levels at high return periods and a small spread 
Fig. 7 Whisker plots of Kolmogorov-Smirnov test statistic of the cumulative precipitation distribution of the $7 \mathrm{CPs}$ using CHR08 reference for winter (a) and summer (b), with uncorrected ESSENCE output (black), results from the NoCP-method (grey) and the CP-method (dark grey). Black thick horizontal lines in each whisker plot indicate the median of the 17 members while the solid box shows the 25 th to 75 th percentiles range of the sample and the whisker show the data range. The whiskers extend to 1.5 times the interquantile range above the top and below the bottom of the box, while the outliers (black dots) mark individual data points that lie beyond the whiskers
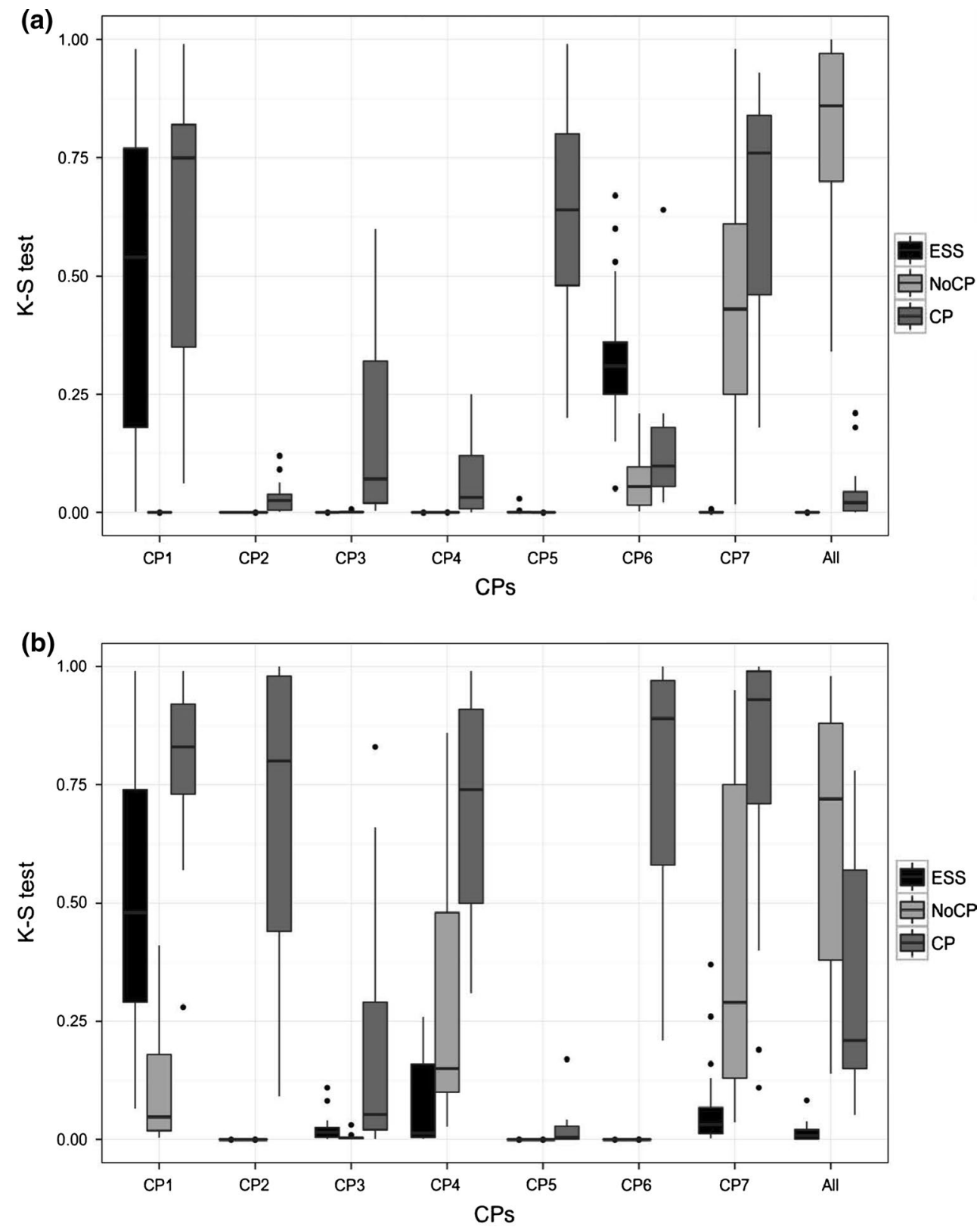

of the 50 year return levels across the ensembles. The $\mathrm{CP}$ correction improves the low return periods but reduces high precipitation rates for the 10 and 20 years return periods (Fig. 8b). The method also decreases the spread at longer return levels, in respect to the spread of the NoCP method. In the summer season, ESSENCE is performing quite well, with a better behavior for the low return periods than in winter. An overestimation in precipitation levels is present for return periods $>5$ years (Fig. 8c). Both $\mathrm{CP}$ and NoCP methods retain the good behavior and the original spread of the ensemble members at return periods $>20$ years (Fig. 8d).

Figure 9 presents the comparison between return times of 5 day precipitation sums from observations and uncorrected and corrected outputs from the CMIP5 ensemble averaged over the Rhine basin for the winter season and summer season. The CMIP5 models display a behavior similar to the ESSENCE model concerning the performance in winter and summer. The CMIP5 ensemble has a smaller spread in the summer than in winter for large return periods (Fig. 9c). The uncorrected CMIP5 precipitation outputs in winter (Fig. 9a) overestimate the observations for low return periods and significantly underestimate for moderate and high return periods. Both $\mathrm{CP}$ and NoCP methods in Fig. 9b correct the low returns periods satisfactory, with the CP method decreasing slightly more the spread of the ensemble. In the summer season, the 
Fig. 8 Return periods of 5-day averaged precipitation sums over the Rhine basin for the ESSENCE ensemble (grey dots) and the CHR08 observations (black line). Top row shows winter ESSENCE uncorrected outputs (a) and corrected using the $\mathrm{CP}$ method (light blue crosses) and NoCP (light grey) (b), while bottom row shows summer uncorrected outputs (c) and corrected (d)
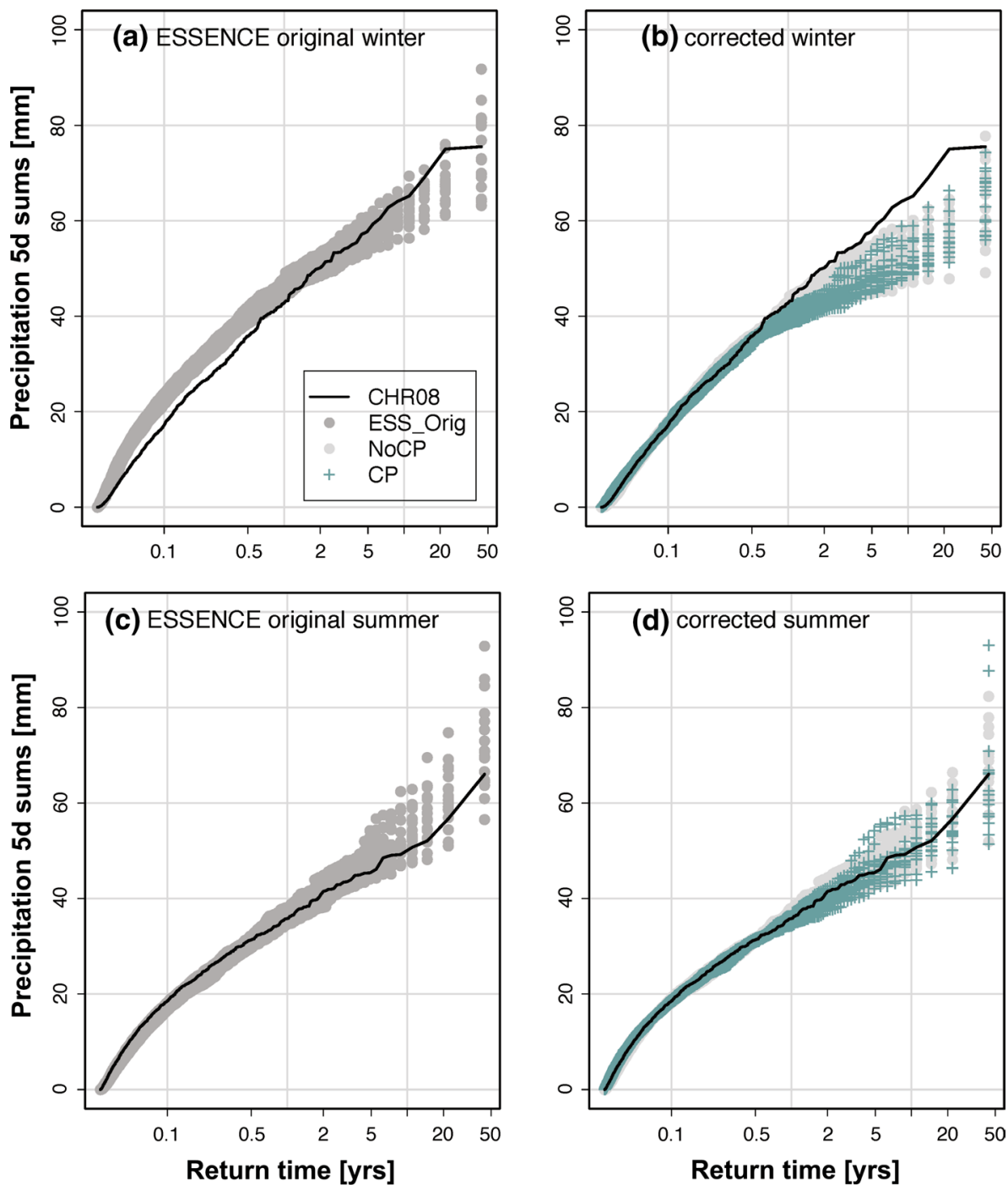

CP-method corrects the bias in low precipitation sums similar to the NoCP method. Concerning high precipitation levels, both NoCP and CP increase the spread; while at return levels between 5 and 20 year the $\mathrm{CP}$ performs better than the NoCP (Fig. 9c, d).

The changes in distribution characteristics between uncorrected and corrected ensembles show that in winter these changes are more obvious than in the summer due to larger correction factors imposed by the correction methods (CP \& NoCP). This is especially obvious in the ESSENCE ensemble and not so distinct in the CMIP5 ensemble. In the CMIP5 ensemble the changes are distinct and similar in both seasons, with the biggest improvement in the lower quantiles. The different changes between winter and summer are related to a stronger dependence of precipitation on circulation in winter, when the pressure gradients are steeper than in summer.

\subsection{Evaluation of simulated discharge}

To demonstrate the effects of the bias correction methods on the estimated discharge for the Rhine basin, the HBV-96 hydrological model was forced with the uncorrected ESSENCE and CMIP5 models precipitation and the respective $\mathrm{CP}$ and NoCP corrected precipitation. Here we present results for Lobith, the entrance point of Rhine in the Netherlands, and Basel, representing the Swiss basin. For winter and summer two different basins were analyzed in more detail, corresponding to the spatiotemporal characteristics of climatic changes in these subbasins. In the alpine part of the Rhine (upstream of Basel) winter discharges increase and spring flows decline between May and October (summer season in this study: April to September), due to a reduction in snowfall, an increase in glacier melt, and an increase in winter precipitation. In the central part of the Rhine basin (upstream of Lobith), flows 
Fig. 9 Return periods of 5-day averaged precipitation sums over the Rhine basin for the CMIP5 ensemble ( grey dots) and the CHR08 observations (black line). Top row shows winter CMIP5 uncorrected outputs (a) and corrected using the $\mathrm{CP}$ method (light blue crosses) and NoCP (light grey) (b), while bottom row shows summer uncorrected outputs (c) and corrected (d)
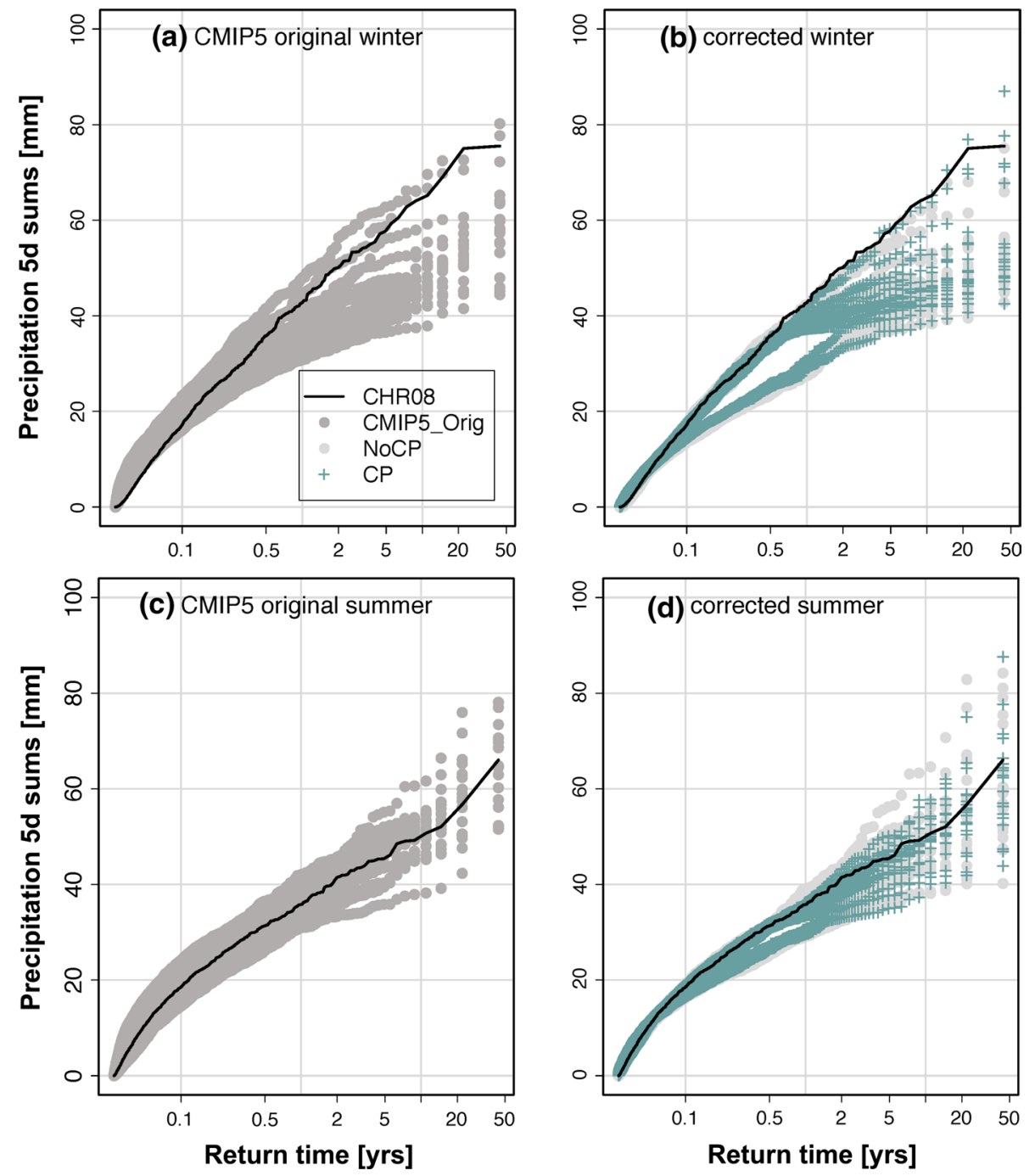

are simulated to increase between February and July, and to decrease at other times. This pattern reflects the annual changes in precipitation.

Figures 10 and 11 present the calculated annual maximum discharges and the fitted peak levels with a return time up to $1 / 100$ year using the discharge obtained by using CHR08 as a forcing as reference. This discharge time series is referred to as "observed" in the following. To match the record length of CHR (1961-2008) HBV-96 model runs were performed for a period of similar length (corresponding to the climate forcing imposed during the period 1961-2005). The extreme discharges levels with long return times are estimated from the data using a Gumbel fit (Coles 2001). In Fig. 10a the $95 \%$ confidence interval of the 100 year return period of the observed and the corrected ESSENCE-driven results for Basel are shown. In winter, the CP method leads to a reduced $95 \%$ confidence range of the 100 year return time compared to the NoCP, which underestimates this range. For the summer season at
Lobith, both correction methods lead to a similar and satisfactory reduction of the uncertainty range.

The estimated annual maximum discharge derived from CMIP5 model output has a wider range of uncertainties for both winter and summer than the ESSENCE ensemble (Figs. 10, 11). Concerning the effect of the bias correction, in winter at Basel (Fig. 11a), both correction methods have larger ranges than the observed, with the $\mathrm{CP}$ correction having a smaller range of uncertainty than the NoCP method. In the summer season at Lobith (Fig. 11b) both methods behave similar; they show larger ranges than the observed, with both methods underestimating the lower margin of the confidence interval. Both NoCP and CP for both locations and half-year seasons lead to a significant reduction in the confidence range compared to the uncorrected discharge record. For CMIP5 and ESSENCE, the uncorrected discharge record shows a different behavior. In Fig. 11a, the observations are situated in the middle of the confidence interval, while in Fig. 10a the ESSENCE ensemble shows 

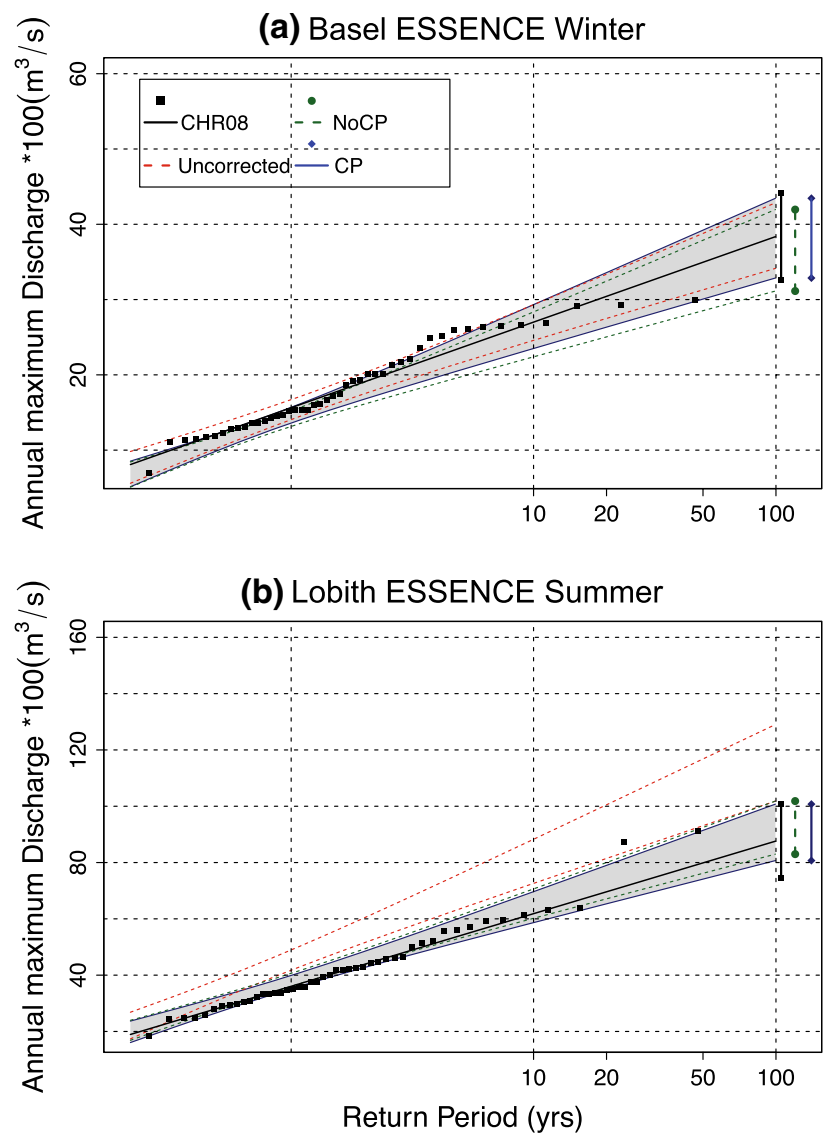

Fig. 10 Gumbel fits of return time of simulated discharges at Lobith for a summer and b winter, estimated using HBV-96 calculations driven by CHR08 data (black solid line), uncorrected ESSENCE model outputs (red dotted lines), ESSENCE NoCP-corrections (green lines) and $\mathrm{CP}$-corrections (blue lines). The grey range indicates the $95 \%$ confidence intervals for the ensemble for the CP-method

an excellent agreement with the observed range. At Lobith, however ESSENCE overestimates the range of the confidence intervals for all return levels.

\section{Discussion and conclusions}

This study assesses the effects of introducing circulation patterns into a bias correction method for precipitation generated by two ensembles of climate model simulations. Specifically an evaluation of simulated discharge from the Rhine basin is carried out. The (co)variability of precipitation over the Rhine basin with regional circulation patterns was analyzed using a MCA for winter and summer half-year data for the period 1961-2005. For each season three leading principal components (PCs) were derived using ERA daily averaged sea level pressure (SLP) and a new high-resolution regional daily precipitation dataset (CHR08). The selected PCs explain a large fraction of the
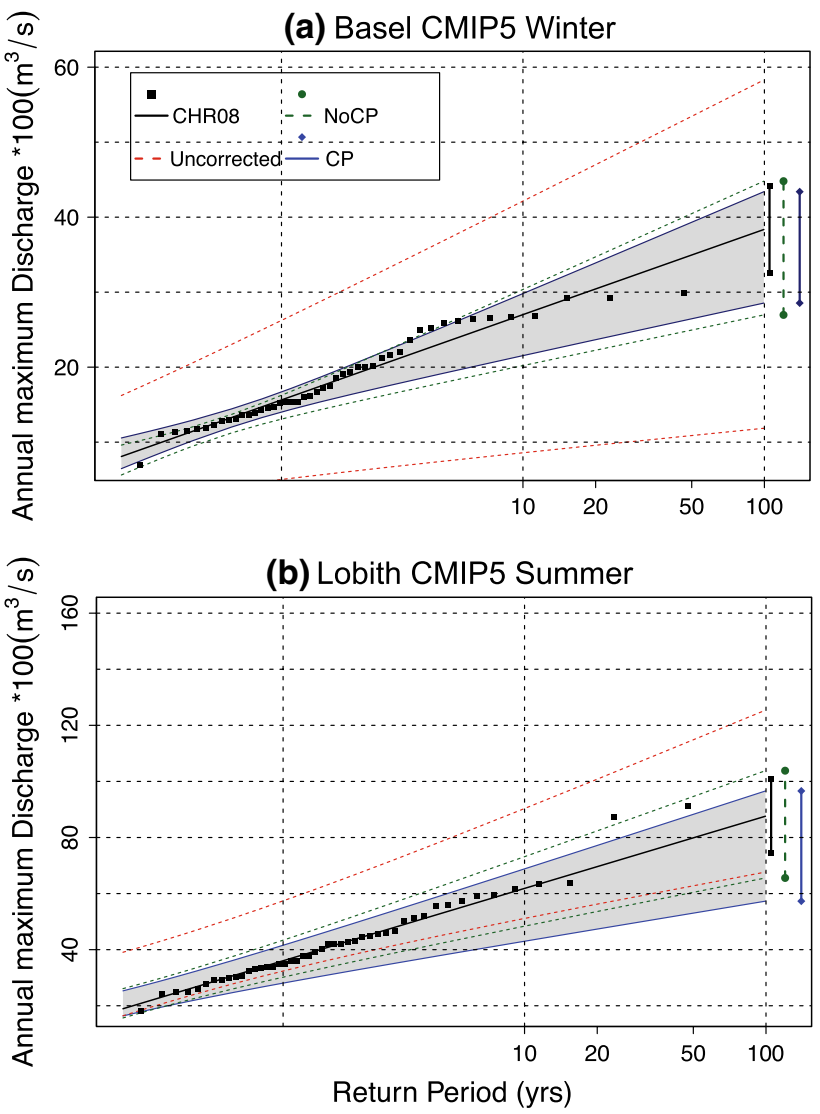

Fig. 11 Gumbel fits of return time of simulated discharges at Lobith for a summer and b winter, estimated using HBV-96 calculations driven by CHR08 data (black solid line), uncorrected CMIP5 model outputs (red dotted lines), CMIP5 NoCP-corrections (green lines) and $\mathrm{CP}$-corrections (blue lines). The grey range indicates the $95 \%$ confidence intervals for the ensemble for the CP-method

variability of precipitation in the Rhine basin, and are in agreement with previous studies (Zveryaev 2009; Bárdossy 2010a). Each 5 day interval was categorized to a given PC according to the sign and amplitude of PC time series, resulting in 6 classified and one unclassified (containing the residuals) sets of circulation patterns (CPs). The $\mathrm{CP}$ categories reflect local and regional pressure gradients; NAOrelated westerlies and easterlies in both winter and summer season can be described successfully using the MCA and can explain a large fraction of the seasonal precipitation variability of the Rhine basin. In the CP-method transformation coefficients are estimated using the quantiles of observed and model precipitation distribution of each $\mathrm{CP}$ precipitation category (Eq. 6).

In both seasons, the frequency of occurrence of the classified CPs in an ECHAM5 climate model ensemble (referred to as the ESSENCE ensemble) shows a smaller bias than CMIP5. The CP-bias correction that makes use of these circulation characteristics thus has a stronger effect in the CMIP5 ensemble than in ESSENCE, implying that 
the CP-specific bias correction has a larger impact for models that have a stronger bias in the circulation distribution statistics.

Changes in extreme precipitation statistics result from a mixture of processes, including changes in the frequency distribution of circulation patterns. Biases in these processes in current climate models form a major source of uncertainty (Cattiaux et al. 2012, 2013; Chen 2013). An attempt for a physical interpretation of the circulation-specific bias of precipitation and the frequency of these patterns did not lead to a clear picture. However, we demonstrate that adding circulation bias into the correction can improve the overall extreme precipitation and estimated extreme discharges. For both winter and summer a nonlinear bias correction not dependent on CPs (referred to as NoCP) has a higher overall skill (as measured by a Kolmogorov-Smirnov test) than the CP-method when the complete cumulative distribution of 5-day precipitation data is considered. The CP method is based on 60 and 95-percentile values in subsets of the sample, and the according precipitation values have different percentile values in the whole sample, causing non-representative transformation coefficients for the entire distribution. This limitation, however, does not lead to an overall deterioration of the performance of the CP-method: especially for extreme discharge over the Rhine the good performance of the CP-method is retained. In addition, for episodes subject to a particular circulation regime, the $\mathrm{CP}$ correction shows a clearly larger $\mathrm{K}-\mathrm{S}$ significance than NoCP, which demonstrates the influence of circulation regimes on precipitation model bias. In particular, the CP-method recognizes the relationship between low/high precipitation rates and specific circulation patterns, where the NoCP-method does not make this explicit attribution. Our results are in line with the findings of (Lisniak et al. 2012), who included an atmospheric circulation index to downscale coarse resolution precipitation data using a Multiplicative Random Cascade method.

The hydrological application in ESSENCE and CMIP5 models presented here shows a significant improvement of both NoCP and CP-corrections for winter in Basel and summer in Lobith. The NoCP performs better than the CP in Lobith, while the $\mathrm{CP}$ correction performs better in winter in the Alpine region. The different performances between $\mathrm{CP}$ and NoCP show primarily the dependence of the precipitation on the circulation regimes in the Alpine (due to the topography).

The CP-method allows improvements in the simulation of precipitation changes that are associated to changes in the circulation regime and the frequency of occurrence of the corresponding CPs. The improvement in the precipitation correction leads to improvements in the estimation of extreme discharges in the Rhine basin. In this framework, we allow for physical connection of the bias in precipitation with circulation patterns without violating the good performance of the delta factor correction. However, a simple bias correction (NoCP) still remains a better option, since with less calculation of parameters the NoCP produces similar improvements.

Physics and feedbacks between precipitation, evaporation and atmospheric dynamics vary widely across circulation regimes and may lead to circulation dependent biases (Christensen et al. 1997; Findell and Eltahir 2003; Seneviratne et al. 2006; Suklitsch et al. 2011). One potential key mechanism to consider in hydrological application in such studies is the interception evaporation process that plays a significant role during low flow conditions in summer and fall (Hurkmans et al. 2009). CP-specific bias corrections may appear beneficial for studding these feedbacks, but this is subject for future research.

Open Access This article is distributed under the terms of the Creative Commons Attribution 4.0 International License (http://creativecommons.org/licenses/by/4.0/), which permits unrestricted use, distribution, and reproduction in any medium, provided you give appropriate credit to the original author(s) and the source, provide a link to the Creative Commons license, and indicate if changes were made.

\section{References}

Bárdossy A (2010a) Atmospheric circulation pattern classification for South-Germany using hydrological variables. Phys Chem Earth $35: 498-506$

Bárdossy A (2010b) Atmospheric circulation pattern classification for South-West Germany using hydrological variables. Phys Chem Earth Parts A/B/C 35:498-506. doi:10.1016/j.pce.2010.02.007

Bárdossy A, Pegram G (2011) Downscaling precipitation using regional climate models and circulation patterns toward hydrology. Water Resour Res 47:1-18. doi:10.1029/2010WR009689

Berglöv G, German J, Gustavsson H, Harbman U, Johansson B (2009) Improvement HBV model Rhine in FEWS, Final report.-Hrsg. Swedish Meteorological and Hydrological Institute, Norrköping, Sweden, SMHI Hydrology report No. 112

Bergström S (1976) Development and application of a conceptual runoff model for Scandinavian catchments. Department of Water Resources Engineering, Bull. Ser. A, No. 52., Lund Institute of Technology, University of Lund, Lund, p 134

Bergström S, Forsman A (1973) Development of a conceptual deterministic rainfall-runoff model. Nord Hydrol 4:147-170

Bertacchi Uvo C, Olsson J, Morita O et al (2001) Statistical atmospheric downscaling for rainfall estimation in Kyushu Island, Japan. Hydrol Earth Syst Sci 5:259-271. doi:10.5194/ hess-5-259-2001

Bretherton CS, Smith C, Wallace JM (1992) An intercomparison of methods for finding coupled patterns in climate data. J Clim 5:541-560. doi:10.1175/1520-0442(1992)005<0541:AIOMFF> 2.0.CO;2

Buishand TA, Brandsma T (1996) Rainfall Generator for the Rhine catchment: a feasibility study. KNMI Publ. ISBN 9036920965

Castaings W, Dartus D, Le Dimet F-X, Saulnier G-M (2009) Sensitivity analysis and parameter estimation for distributed hydrological modeling: potential of variational methods. Hydrol Earth Syst Sci 13:503-517. doi:10.5194/hess-13-503-2009 
Cattiaux J, Quesada B, Arakélian A et al (2012) North-Atlantic dynamics and European temperature extremes in the IPSL model: sensitivity to atmospheric resolution. Clim Dyn 40:22932310. doi:10.1007/s00382-012-1529-3

Cattiaux J, Douville H, Peings Y (2013) European temperatures in CMIP5: origins of present-day biases and future uncertainties. Clim Dyn 41:2889-2907. doi:10.1007/s00382-013-1731-y

Chen H (2013) Projected change in extreme rainfall events in China by the end of the 21st century using CMIP5 models. Chin Sci Bull 58:1462-1472. doi:10.1007/s11434-012-5612-2

Christensen JH, Machenhauer B, Jones RG et al (1997) Validation of present-day regional climate simulations over Europe: LAM simulations with observed boundary conditions. Clim Dyn 13:489-506

Clark MP, Gangopadhyay S, Brandon D et al (2004) A resampling procedure for generating conditioned daily weather sequences. Water Resour Res. doi:10.1029/2003WR002747

Coles S (2001) An introduction to statistical modeling of extreme values. Springer Series in Statistics. Springer, London

Dee DP, Uppala SM, Simmons AJ et al (2011) The ERA-Interim reanalysis: configuration and performance of the data assimilation system. Q J R Meteorol Soc 137:553-597. doi:10.1002/qj.828

Disse M, Engel H (2001) Flood events in the Rhine basin: genesis, influences and mitigation. Nat Hazards 23:271-290. doi:10.102 3/a:1011142402374

Eberle M, Buiteveld H, Krahe P, Wilke K (2005) Hydrological modelling in the river Rhine basin, part III: Daily HBV model for the Rhine basin, Report 1451. Koblenz, Germany

Findell KL, Eltahir EAB (2003) Atmospheric controls on soil moisture-boundary layer interactions: three-dimensional wind effects. J Geophys Res Atmos. doi:10.1029/2001JD001515

Fowler HJ, Blenkinsop S, Tebaldi C (2007) Linking climate change modelling to impacts studies: recent advances in downscaling techniques for hydrological modelling. Int J Climatol 27:15471578. doi:10.1002/joc. 1556

Frei C, Davies HC, Gurtz J, Schär C (2001) Climate dynamics and extreme precipitation and flood events in Central Europe. Integr Assess 1(4):281-299. doi:10.1023/A:1018983226334

Friederichs P, Hense A (2007) Statistical downscaling of extreme precipitation events using censored quantile regression. Mon Weather Rev 135:2365-2378. doi:10.1175/MWR3403.1

Goodess CM, Anagnostopoulou C, Bárdossy A et al (2012) An intercomparison of statistical downscaling methods for Europe and European regions-assessing their performance with respect to extreme temperature and precipitation events 2005 (published as CRU RP11 in 2012). Climatic Research Unit School of Enviro. CRU RP11

Hagemann S, Chen C, Haerter JO et al (2011) Impact of a statistical bias correction on the projected hydrological changes obtained from three GCMs and two hydrology models. J Hydrometeorol 12:556-578. doi:10.1175/2011JHM1336.1

Haylock MR, Goodess CM (2004) Interannual variability of European extreme winter rainfall and links with mean large-scale circulation. Int J Climatol 24:759-776. doi:10.1002/joc.1033

Haylock M, Hofstra N, Tank AK, Klok E, Jones P, New M (2008) A European daily high-resolution gridded data set of surface temperature and precipitation for 1950-2006. J Geophys Res 113:D20119. doi:10.1029/2008JD010201

Hundecha Y, Bárdossy A (2008) Statistical downscaling of extremes of daily precipitation and temperature and construction of their future scenarios. Int J Climatol 28:589-610. doi:10.1002/ joc. 1563

Hurkmans RTWL, Terink W, Uijlenhoet R et al (2009) Effects of land use changes on streamflow generation in the Rhine basin. Water Resour Res. doi:10.1029/2008WR007574

Hurrell JW (1995) Decadal trends in the North Atlantic Oscillation: regional temperatures and precipitation. Science. doi:10.1126/ science.269.5224.676
Huth R (1999) Statistical downscaling in central Europe: evaluation of methods and potential predictors. Clim Res 13:91-101

Ionita M, Lohmann G, Rimbu N, Chelcea S (2011) Interannual variability of Rhine River streamflow and its relationship with largescale anomaly patterns in spring and autumn. J Hydrometeorol 13:172-188. doi:10.1175/JHM-D-11-063.1

Jagger TH, Elsner JB (2009) Modeling tropical cyclone intensity with quantile regression. Int J Climatol 29:1351-1361. doi:10.1002/ joc. 1804

Jones PD, Lister DH (2009) The influence of the circulation on surface temperature and precipitation patterns over Europe. Clim Past 5:259-267. doi:10.5194/cp-5-259-2009

Kew SF, Selten FM, Lenderink G, Hazeleger W (2011) Robust assessment of future changes in extreme precipitation over the Rhine basin using a GCM. Hydrol Earth Syst Sci 15:1157-1166. doi: 10.5194/hess-15-1157-2011

Leander R, Buishand TA (2007) Resampling of regional climate model output for the simulation of extreme river flows. J Hydrol 332:487-496

Lindström G, Johansson B, Persson M et al (1997) Development and test of the distributed HBV96 hydrological model. J Hydrol 201:272-288. doi:10.1016/S0022-1694(97)00041-3

Lisniak D, Frnake J, Bernhofer C (2012) Circulation pattern based parameterization of a multiplicative random cascade for disaggregation of daily rainfall under nonstationary climatic conditions. Hydro Earth Syst Sci Discuss 9:10115-10149

Maraun D, Wetterhall F, Ireson AM et al (2010) Precipitation downscaling under climate change: recent developments to bridge the gap between dynamical models and the end user. Rev Geophys. doi:10.1029/2009RG000314

Martín ML, Valero F, Pascual A et al (2011) Springtime connections between the large-scale sea-level pressure field and gust wind speed over Iberia and the Balearics. Nat Hazards Earth Syst Sci 11:191-203. doi:10.5194/nhess-11-191-2011

Nakicenovic N, Swart R (eds) (2000) Emission scenarios: a special report of Working Group III of the Intergovernmental Panel on Climate Change. Cambridge University Press, Cambridge, UK

Pfister L, Kwadijk J, Musy A et al (2004) Climate change, land use change and runoff prediction in the Rhine-Meuse basins. River Res Appl 20:229-241. doi:10.1002/rra.775

Photiadou CS, Weerts AH, van den Hurk BJJM (2011) Evaluation of two precipitation data sets for the Rhine River using streamflow simulations. Hydrol Earth Syst Sci 15:3355-3366. doi:10.5194/ hess-15-3355-2011

Polade SD, Gershunov A, Cayan DR et al (2013) Natural climate variability and teleconnections to precipitation over the PacificNorth American region in CMIP3 and CMIP5 models. Geophys Res Lett 40:2296-2301. doi:10.1002/grl.50491

Seneviratne SI, Luthi D, Litschi M, Schar C (2006) Land-atmosphere coupling and climate change in Europe. Nature 443:205-209

Slonosky VC, Jones PD, Davies TD (2000) Variability of the surface atmospheric circulation over Europe, 17741995. Int J Climatol 20:1875-1897. doi:10.1002/10970088(200012)20:15<1875:AID-JOC593>3.0.CO;2-D

Sprokkereef E (2001) Eine hydrologische datenbank für das rheingebiet, report. International Commision for the Hydrology of the Rhine Basin (CHR), Arnhem, Netherlands

Stahl K, Demuth S (1999) Linking streamflow drought to the occurrence of atmospheric circulation patterns. Hydrol Sci J 44:467482. doi:10.1080/02626669909492240

Sterl A, Severijns C, Dijkstra H et al (2008) When can we expect extremely high surface temperatures? Geophys Res Lett. doi:10. 1029/2008GL034071

Suklitsch M, Gobiet A, Truhetz H et al (2011) Error characteristics of high resolution regional climate models over the Alpine area. Clim Dyn 37:377-390 
Taylor KE, Stouffer RJ, Meehl GA (2012) An overview of CMIP5 and the experiment design. Bull Am Meteorol Soc 93:485-498. doi:10.1175/BAMS-D-11-00094.1

Tu M (2006) Assessment of the effects of climate variability and land use change on the hydrology of the Meuse river basin. Ph.D thesis, Vrije Universiteit Amsterdam, Amsterdam, The Netherlands and UNESCOIHE, Delft, The Netherlands

Ulbrich U, Fink A (1995) The January 1995 flood in Germany: meteorological versus hydrological causes. Phys Chem Earth 20:439444. doi:10.1016/S0079-1946(96)00002-X

Uppala SM, KÅllberg PW, Simmons AJ et al (2005) The ERA-40 re-analysis. Q J R Meteorol Soc 131:2961-3012. doi:10.1256/ qj.04.176

Van Haren R, Jan G, Geert VO (2012) SST and circulation trend biases cause an underestimation of European precipitation trends. Clim Dyn 40:1-20

Van Haren R, van Oldenborgh GJ, Lenderink G, Hazeleger W (2013) Evaluation of modeled changes in extreme precipitation in Europe and the Rhine basin. Environ Res Lett 8:14053

Van Pelt SC, Beersma JJ, Buishand TA et al (2012) Future changes in extreme precipitation in the Rhine basin based on global and regional climate model simulations. Hydrol Earth Syst Sci 16:4517-4530. doi:10.5194/hess-16-4517-2012

Van Ulden AP, van Oldenborgh GJ (2006) Large-scale atmospheric circulation biases and changes in global climate model simulations and their importance for climate change in Central Europe. Atmos Chem Phys 6:863-881. doi:10.5194/ acp-6-863-2006

Von Storch H, Navara A (1995) Analysis of climate variability. Springer, Berlin

Von Storch H, Zwiers FW (1999) Statistical analysis in climate research. Cambridge University Press, Cambridge

Wang C, Zhang L, Lee S-K et al (2014) A global perspective on CMIP5 climate model biases. Nat Clim Change 4:201-205

Wibig J (1999) Precipitation in Europe in relation to circulation patterns at the $500 \mathrm{hPa}$ level. Int J Climatol 19:253-269. doi:10.1002/ (SICI)1097-0088(19990315)19:3<253:AID-JOC366>3.0.CO;2-0

Wilby R, Wigley T, Conway D, Jones P (1998a) Statistical downscaling of general circulation model output: a comparison of methods. Water Resour 34:2995-3008

Wilby RL, Hassan H, Hanaki K (1998b) Statistical downscaling of hydrometeorological variables using general circulation model output. J Hydrol 205:1-19

Zveryaev II (2009) Interdecadal changes in the links between European precipitation and atmospheric circulation during boreal spring and fall. Tellus A 61:50-56. doi:10.1111/j.1600-0870.2008.00360.x 